\title{
Building the Long-term Picture: \\ The U.S. JGOFS Time-series Programs
}

\author{
David M. Karl, John E. Dore and Roger Lukas \\ University of Hawaii • Honolulu, Hawaii USA
}

Anthony F. Michaels

University of Southern California - Los Angeles, California USA

\author{
Nicholas R. Bates and Anthony Knap \\ Bermuda Biological Station for Research . Ferry Reach, Bermuda
}

\section{Introduction}

Long-term time-series studies are ideally suited for investigation of the subtle habitat changes, irregularly spaced stochastic events and complex interdependent ecological phenomena that affect biogeochemical cycles in the world ocean. In 1986, during the early planning stages of what would eventually become the U.S. Joint Global Ocean Flux Study (JGOFS), timeseries studies were identified as crucial for assessing the baseline or mean states of key parameters in the oceanic carbon cycle and their variability. They were patterned initially after the VERtical Transport and EXchange (VERTEX) time-series study then underway in the northeast Pacific Ocean, but the VERTEX field program, which included six cruises and lasted for 18 months, proved to be too short in length and the observations too infrequent to resolve much of the natural variability in open-ocean ecosystems. This discovery presented a scientific and logistical challenge for JGOFS planners.

The process-oriented field studies that took place during JGOFS captured only part of the variability that is characteristic of oceanic biogeochemical processes. They were carried out in specific geographical regions to study important physical-biogeochemical interactions, such as the vernal blooming of the North Atlantic Ocean and the monsoonal forcing of the ecosystems in the surface waters of the Arabian Sea. But capturing the unpredictable, larger-scale and lower-frequency climate variations associated with the El Niño-Southern Oscillation (ENSO), Pacific Decadal Oscillation (PDO) and North Atlantic Oscillation (NAO) was, for the most part, beyond the scope of these process studies. These climate oscillations, which occur irregularly on subseasonal to decadal time scales, may have profound effects on ocean biogeochemistry and on the net balance of carbon between the atmosphere and the ocean. Severe storms, atmospheric deposition, mesoscale features of ocean circulation, volcanic eruptions, extended periods of elevated precipitation or evaporation, repositioning of largescale atmospheric circulation features and the warming associated with rising levels of greenhouse gases are among the many ecologically relevant physical forces at work in the coupled ocean-atmosphere system.

Some climatic perturbations lead to increases in turbulent entrainment or upwelling and thus to a redistribution of essential macro- and micronutrients in the upper water column. Increased availability of nutrients leads, in turn, to increases in primary production and, depending on the scale and duration of the disturbance, to changes in populations at higher trophic levels and in the export of dissolved and particulate organic matter. Other perturbations alter near-surface stratification, isolating the upper ocean from the large reservoir of essential nutrients found in the deeper portion of the water column and leading to a variety of ecological consequences. The effects of these processes on ecosystem structure and functioning cannot be observed during any single oceanographic expedition, no matter how well-planned or fortunate. To study these aperiodic events and long-term trends, one must go to sea month after month over many years to observe the natural scales of habitat and ecosystem variability accurately.

\section{Shifting Ecosystem Paradigms: The Marine Microbiological Revolution}

When planning for U.S. JGOFS began in the mid 1980s, we thought we had a reasonably comprehensive understanding of the marine carbon cycle. The "Redfield ratio," which specifies a persistent elemental ratio of carbon to nitrogen to phosphorus in the ocean, was widely accepted (see also Michaels et al., in this issue). Oceanographers had been working with a basic understanding of new versus regenerated organic matter production for two decades (Dugdale and Goering, 1967), and a publication in 1979 (Eppley and Peterson) 
melded new production with the export flux of organic particles in the open ocean. The microbial loop/foodweb paradigm was also well established and verified (Pomeroy, 1974; Azam et al., 1983). These concepts guided the design of the JGOFS program.

Our view of plankton dynamics in the sea has changed radically throughout the JGOFS era, however, forcing a reassessment of some of our basic tenets of biological oceanography and marine carbon-cycle research. In the late 1970s, marine scientists discovered the picophytoplankton, tiny floating organisms primarily of the genus Synechococcus (Johnson and Sieburth, 1979). Just as the JGOFS field studies were getting underway in 1988, the even more abundant genus Prochlorococcus (Chisholm et al., 1988) was discovered. We were faced with the need to accommodate the two most abundant but previously undescribed forms of marine phytoplankton in our ocean carbon-cycle paradigm.

The "marine microbiological revolution" intensified significantly during the 1990s as major technological advances in molecular biology provided new directions for laboratory and field research. In 1992, a new domain of life, the planktonic Archaea, was discovered in the ocean (DeLong, 1992). Morphologically similar to Bacteria, the Archaea are distinctive in their molecular basis for life and, presumably, in their role in the marine carbon cycle. Although they are now recognized as important players in the sea of microbes, little is known about their precise ecological niches.

In 1996, the first full sequencing of the genome of a marine microorganism was completed. With it came the realization that a large percentage of the proteins coded had no readily recognizable function. Researchers hypothesized that this previously undescribed genetic information might be used for survival under variable and sometimes harsh conditions. Recent discoveries of novel biochemical pathways for bacterial photosynthesis (Kolber et al., 2001) and photoheterotrophy (Béjà et al., 2001) in the marine plankton have confirmed the existence of unconventional pathways for carbon and energy flux. There appears to be a large genomic investment in metabolic control and regulation; repressed potential may be unleashed in nature at any time. This new information on the genetic basis for life in the sea has provided exciting clues that help to resolve but also to complicate the carboncycle mystery.

\section{Time-series Implementation Strategies}

In 1988, two U.S. JGOFS time-series stations were established, one in the North Atlantic near Bermuda $\left(31^{\circ} 45^{\prime} \mathrm{N}, 64^{\circ} 10^{\prime} \mathrm{W}\right)$ and the other in the North Pacific near Hawaii $\left(22^{\circ} 45^{\prime} \mathrm{N}, 158^{\circ} \mathrm{W}\right)$. The Bermuda Atlantic Time-series (BATS) and the Hawaii Ocean Time-series (HOT) emerged from the planning process to become twin open-ocean programs with similar scientific objectives, research approaches, sampling frequencies, methods of ecosystem interrogation, and nearly identi- cal suites of core measurements (Figure 1 and Table 1). These core measurements were intended to provide the data sets needed to calibrate, validate and improve biogeochemical models. The proximity of these sites to centers of logistical and intellectual support in Bermuda and Hawaii has been invaluable. Still underway, these programs have yielded data sets that provide a unique and comprehensive picture of oceanic variability and a rich source of testable ecological hypotheses. The BATS and HOT data sets are completely accessible (see sidebars). They and their scientific interpretations (Karl and Michaels, 1996; Siegel et al., 2001) are now part of the U.S. JGOFS legacy.

Ocean time-series observations were not invented by JGOFS. Time-series projects were undertaken in the Baltic and North Seas in the latter portion of the $19^{\text {th }}$ century, and the open-ocean Panulirus Station near Bermuda was initiated in 1954. Until the U.S. JGOFS programs were established, however, there were few multidisciplinary measurement programs focused on the ocean carbon cycle.

Space and time were the primary issues in the initial discussions about establishing time-series sampling programs in JGOFS. Site selection was crucial if the future data sets were to be useful for regional extrapolations or predictions of change. The establishment of JGOFS time-series field studies at sites with previous or ongoing measurement programs at weathership stations or existing time-series sites had the obvious advantages of an existing archive of data and an historical context. JGOFS planners gained invaluable insights from past and ongoing time-series studies, especially the observations of the seasonal cycle of primary production in the Sargasso Sea made by David Menzel and John Ryther in the late 1950s and the 17-year CLIMAX study conducted in the North Pacific subtropical gyre by John McGowan, Thomas Hayward, Elizabeth Venrick, Richard Eppley and others beginning in the mid-1960s.

Sampling frequency and program duration were also key issues for the planners of the JGOFS timeseries programs, who recognized the importance of capturing and interpreting the temporal variability of key biogeochemical processes. Any given time-series data set contains both signal and noise, and signal on one time scale may be noise on another. More frequent data collection and longer time-series records make the separation easier. Monthly shipboard observations over more than a decade have proven effective for documenting subseasonal to interannual variability. But a robust assessment of the decade-scale biogeochemical patterns that are now thought to occur in open ocean ecosystems will probably require a program of at least 30 to 40 years duration and possibly longer.

The JGOFS planners expected the magnitude of variation in carbon stocks and fluxes in response to climate change to be small in comparison with natural variability. The precision and accuracy of measurements, as well as their consistency over time, were cru- 


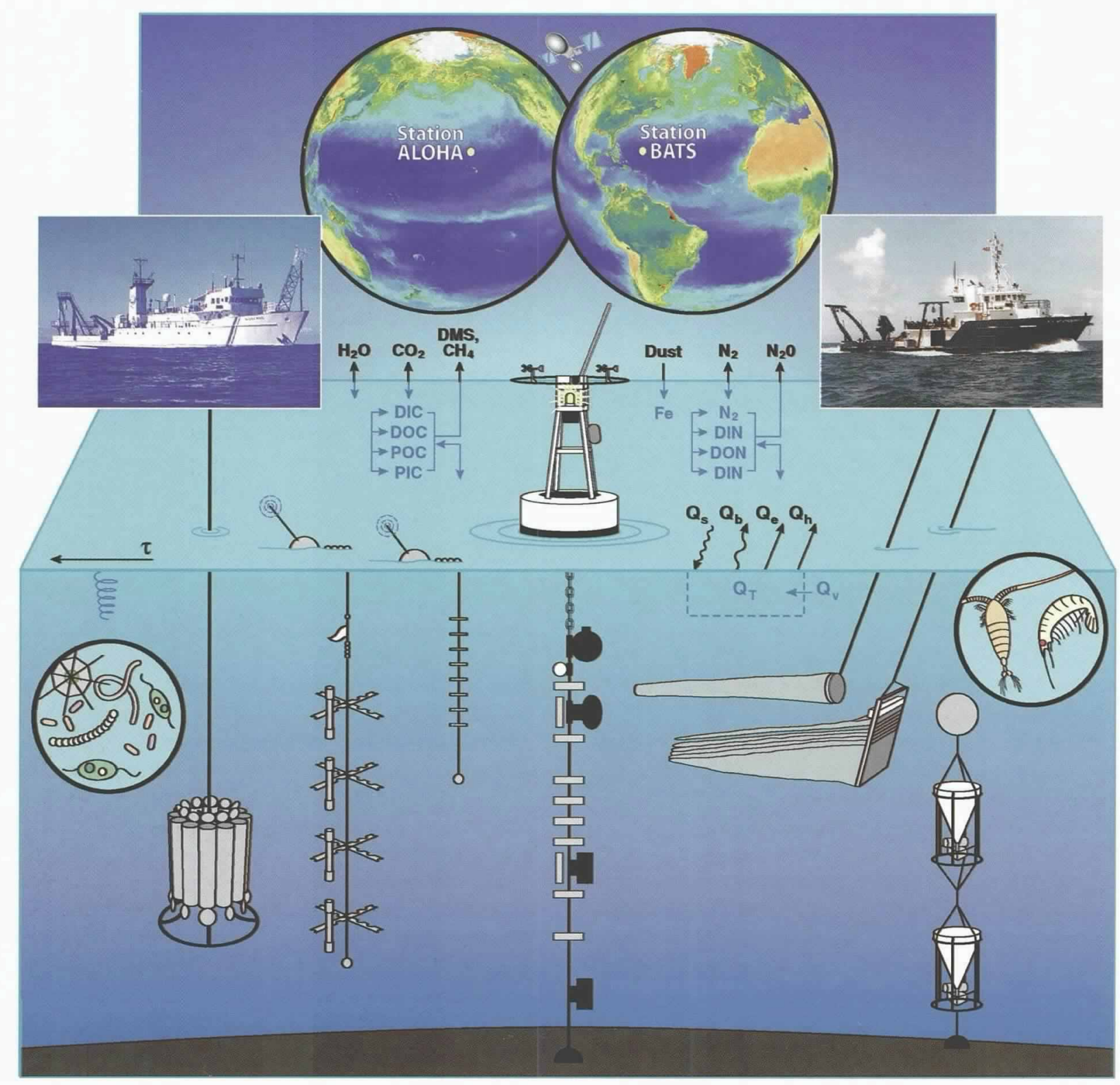

Figure 1. From the macroscope to the microscope, investigations of ocean biogeochemistry at the U.S. JGOFS time-series programs. (Top) Satellite view of the global biosphere based on observations from SeaWiFS (September 1997-August 1998), courtesy of NASA Goddard Space Flight Center and the Orbital Sciences Corporation (Gene Feldman, http://seawifs.gsfc.nasa.gov/SEAWIFS.html). (Left-center and right-center) Research vessels MOANA WAVE and WEATHERBIRD II in the North Pacific and North Atlantic oceans. (Bottom) Some of the ship-based and remote-sampling techniques used in BATS and HOT to obtain information on the cycles of carbon and other biogenic elements in the sea. Important components of these cycles, including dissolved and particulate inorganic and organic pools, are shown in center, along with selected air-sea exchanges, including water exchange through evaporation and precipitation and wind forcing. The total heat budget $\left(Q_{T}\right)$ includes the following fluxes: $Q_{s}$ (solar input), $Q_{b}$ (long wavelength radiation), $Q_{e}$ (evaporation), $Q_{h}$ (conduction) and $Q_{v}$ (advection). Shown in the enclosed circles are microscopic images of nanoplankton (left) and mesozooplankton (right).

cial considerations. The comparison and merging of data sets across measurement programs would demand careful, well-structured quality-control and assurance protocols and frequent interlaboratory comparisons (see Dickson and Hansell sidebars, this issue).

The BATS and HOT programs are organized around field expeditions that take place approximately once a month. Between October 1988, when the field studies began, and the end of December 2000, the two programs have collectively logged approximately 1,300 days at sea and more than 50 person-years of observation and experimentation (Figure 2). Seasonal coverage has been relatively even (Figure 2), a prerequisite for unbiased data and ecological interpretation. At the 


\section{Table 1}

\section{Common core measurements made at the BATS and HOT open-ocean sites $1,2,3$}

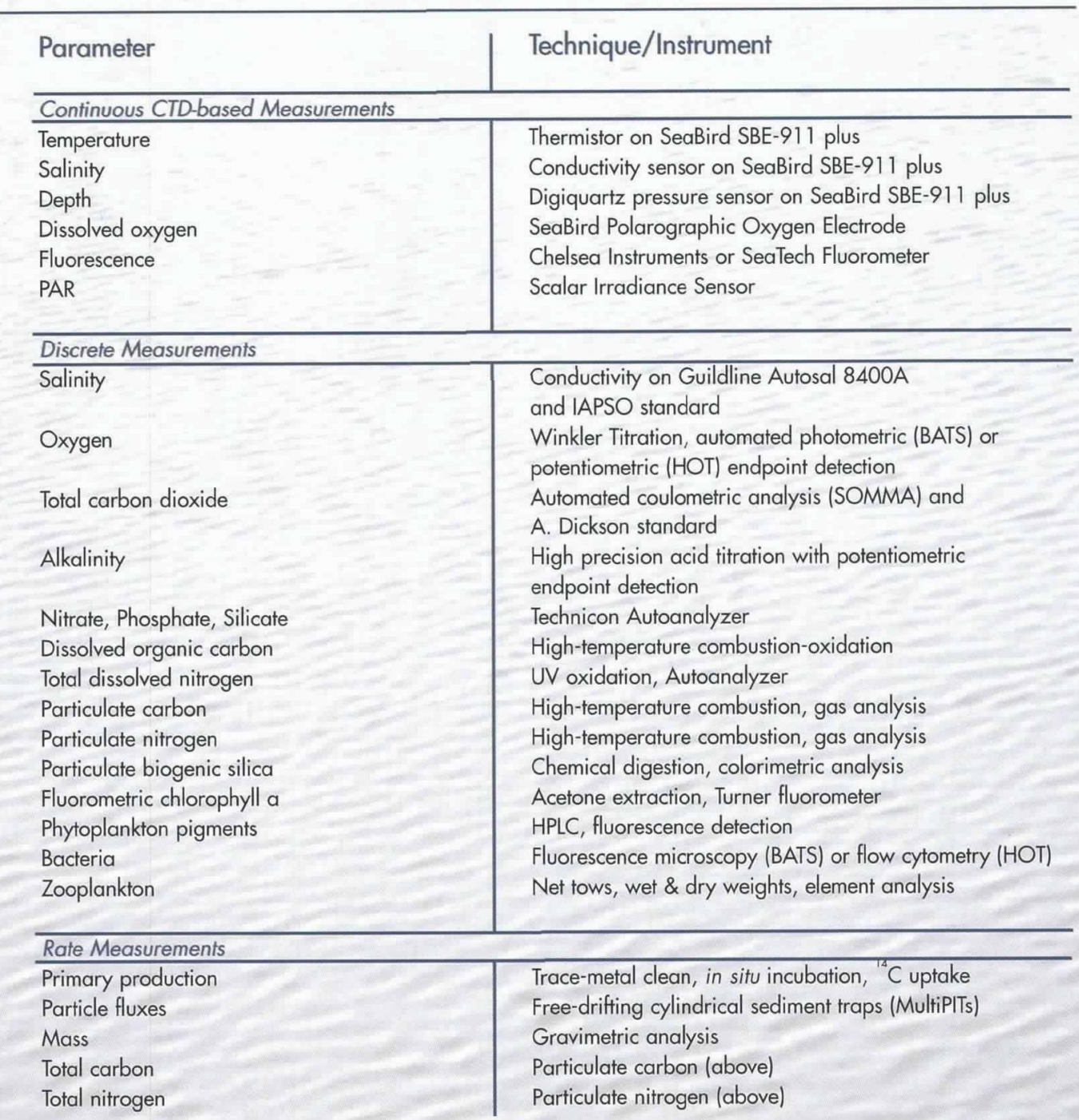

Additional measurements for BATS only include: (a) beam attenuation using a SeaTech $25 \mathrm{~cm}$ transmissometer,

(b) bacterial activity using " $\mathrm{H}$-thymidine incorporation and (c) separation of "total" carbon flux into organic and

inorganic components by acidification of paired sample and CHN analysis and subsequent calculation of inorganic carbon (Total-organic).

${ }^{2}$ Additional measurements for HOT only include: (a) high sensitivity measurements of nitrate using chemiluminescence and phosphate via magnesiuminduced co-precipitation (MAGIC), (b) total dissolved phosphorus using UV oxidation and Autoanalyzer, (c) particulate phosphorus in water column and sediment traps using high-temperature combustion and colorimetry, (d) picophytoplankton enumeration using flow cytometry, (e) ATP using firefly bioluminescence and (f) CTD-dissolved oxygen using the new SeaBird SBE-43 Clark polarographic membrane type sensor.

${ }^{3}$ In addition to these measurements, routine meteorological data including wind speed and direction (anemometer), atmospheric pressure (barometer), wet- and dry-bulb air temperature (psychrometer), cloud type and cover, weather and sea state are also collected.

HOT site, a high-frequency CTD profiling program has also resolved internal tides and inertial variability in the region.

Despite the accomplishments of BATS and HOT, we conclude that monthly observations are too infrequent to resolve all of the significant scales of variability in ocean biogeochemistry. For this reason, both time-series programs have deployed moorings with a variety of instruments and bottom-moored sediment traps for near continuous surveillance (Figure 1). Several satellitemounted instruments have been providing large-scale data on ocean phenomena during the JGOFS era, including the Topography Experiment (TOPEX/POSEIDON) and Earth Resources Satellite (ERS)-2 altimeters for seasurface topography, the National Aeronautics and Space Administration (NASA) scatterometer for sea-surface 


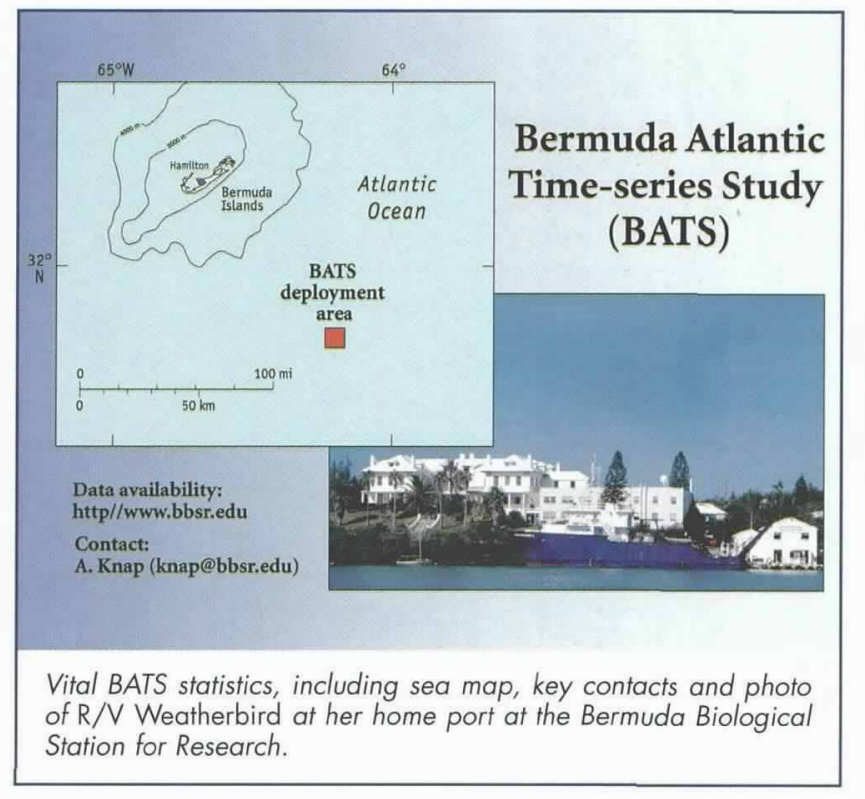

winds and the Sea-viewing Wide Field-of-View Sensor (SeaWiFS) ocean-color imager for estimates of sea-surface chlorophyll. (For more information on satellite observations, see Yoder, this issue. For more information on mooring and sensor-based measurements, see Dickey, this issue).

\section{Comparisons Between The BATS and HOT Sites}

While the subtropical gyres in which BATS and HOT are located share many ecological characteristics, there are also many fundamental differences. Physical differences are related to the locations of the sampling sites in the subtropical gyres. HOT is within the weak

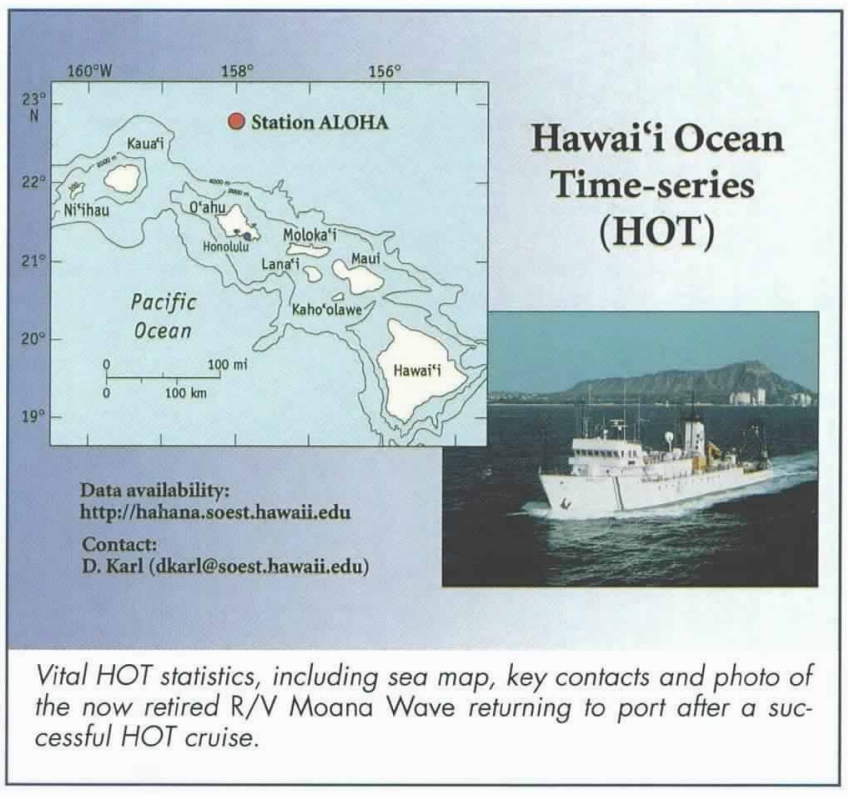

southward return flow of the eastern gyre, while BATS is within the western gyre recirculation. Thus advective influences are quite different. For example, the thermocline is significantly deeper in the western gyre (BATS) than in the east (HOT). Also, patterns of eddies in the eastern gyre (HOT) show much less energetic variability than in the west (BATS). As a result, chronic oligotrophy characterizes the region around the HOT site, whereas a seasonal, summertime oligotrophy occurs near Bermuda.

The magnitude and duration of the recurrent spring phytoplankton bloom at BATS tracks the depth of winter mixing in the water column, which can vary sub-

\section{Table 2}

Variability in primary production $\left({ }^{14} \mathrm{C}\right.$ method), particulate carbon export (measured at $150 \mathrm{~m}$ using sediment traps) and the export ratio (e-ratio) for the 11-year BATS and HOT data sets

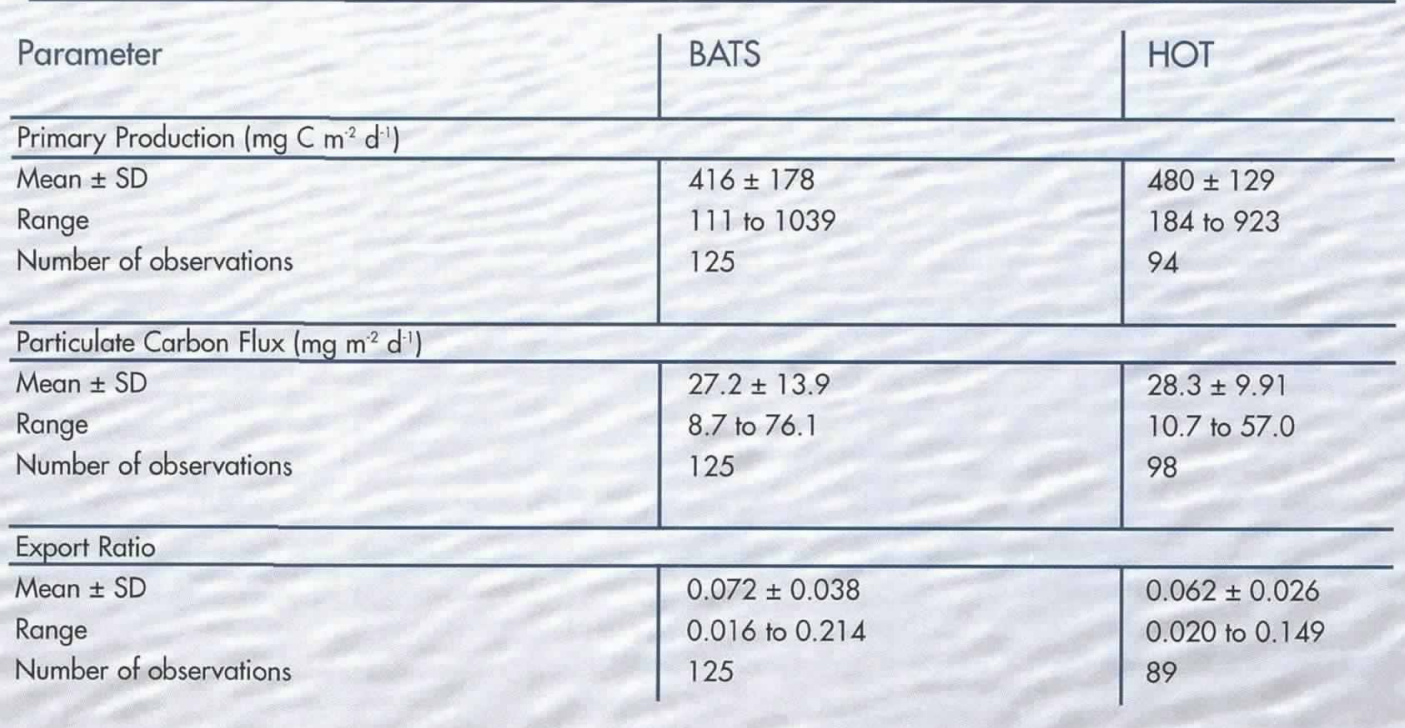


BERMUDA ATLANTIC TIME-SERIES STUDY

\begin{tabular}{|c|c|c|c|c|c|c|c|c|c|c|c|c|}
\hline \multirow{2}{*}{2000} & 9 & 0 & ○ & 0 & 0 & 0 & ○ & 0 & 0 & 0 & 0 & ○ \\
\hline & 0 & 0 & 0 & 0 & e & 0 & 0 & p & 0 & 0 & 0 & 0 \\
\hline \multirow[t]{2}{*}{1998} & 0 & 0 & 0 & 0 & e & 0 & 0 & 0 & 0 & 0 & 0 & 0 \\
\hline & 0 & 0 & $p$ & 0 & 0 & 0 & 0 & 0 & 0 & 0 & 0 & 0 \\
\hline \multirow[t]{2}{*}{1996} & & 0 & 0 & 0 & 0 & 0 & 0 & 0 & p & 0 & 0 & 0 \\
\hline & 0 & 0 & 0 & 0 & 0 & 0 & 0 & 0 & 0 & 0 & 0 & 0 \\
\hline \multirow{2}{*}{$\stackrel{\text { స్ }}{>} 1994$} & 0 & 0 & 0 & 0 & 0 & 0 & 0 & 0 & 0 & 0 & 0 & 0 \\
\hline & 0 & 0 & 0 & 0 & 0 & 0 & 0 & 0 & 0 & 0 & 0 & 0 \\
\hline \multirow[t]{2}{*}{1992} & 0 & 0 & ○ & 0 & - & • & - & 0 & ○ & 0 & 0 & 0 \\
\hline & 0 & 0 & 0 & 0 & 0 & 0 & 0 & 0 & 0 & 0 & ○ & 0 \\
\hline \multirow[t]{2}{*}{1990} & 0 & 0 & - & 0 & 0 & 0 & 0 & 0 & 0 & 0 & 0 & p \\
\hline & 잉 & 0 & 0 & - & • & 0 & 0 & 0 & 0 & 0 & 0 & 0 \\
\hline 1988 & & & & & & & & STA & $R T$ & $\rightarrow 0$ & - & 0 \\
\hline
\end{tabular}

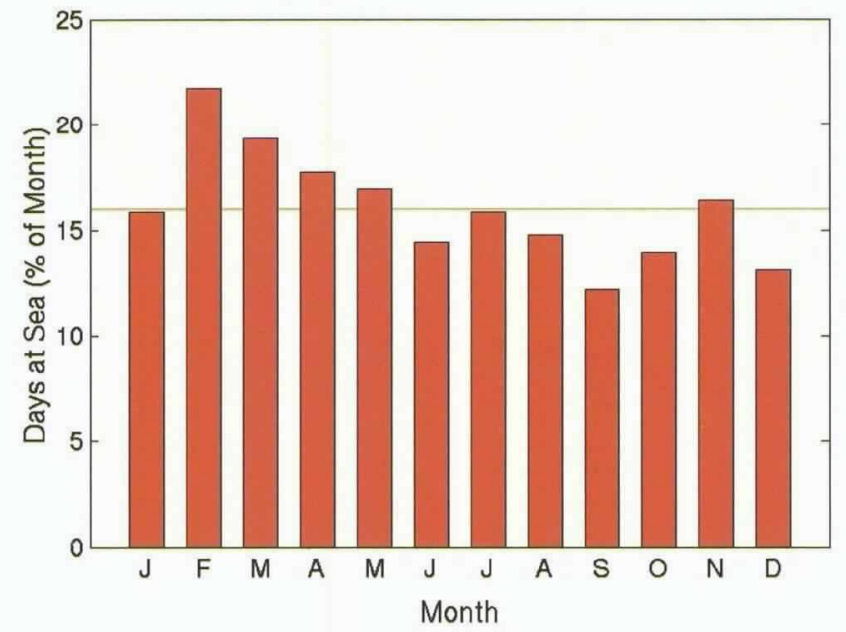

HAWAII OCEAN TIME-SERIES

\begin{tabular}{|c|c|c|c|c|c|c|c|c|c|c|c|}
\hline & $b$ & d & 9 & 0 & 0 & 임 & - & & 0 & & 90 \\
\hline - & - & - & - & - & & • & - & & $\bullet$ & - & - \\
\hline - & - & - & - & - & - & - & 0 & 9 & 1 & $\bullet$ & 0 \\
\hline 0 & 0 & 0 & • & ? & e & 0 & 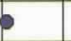 & - & & & - \\
\hline \multirow[t]{2}{*}{ - } & & 9 & 0 & - & 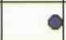 & 9 & 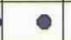 & & 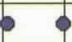 & & - \\
\hline & 0 & c & - & 0 & & 9 & 9 & 0 & 9 & 0 & \\
\hline 0 & 0 & - & & & - & 0 & 9 & 0 & - & - & \\
\hline 0 & 0 & & - & - & & 0 & & - & 0 & 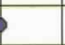 & \\
\hline \multirow[t]{2}{*}{0} & - & 0 & - & & 0 & 0 & 0 & 0 & 0 & 0 & 0 \\
\hline & b & - & 0 & - & 0 & - & - & - & - & & 0 \\
\hline 0 & - & $\bullet$ & - & - & - & - & & • & & - & - \\
\hline \multirow[t]{2}{*}{ - } & & 9 & & - & - & 8 & 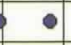 & - & - & 9 & 9 \\
\hline & & & & & & & STAF & RT- & $\rightarrow$ & 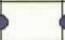 & 6 \\
\hline
\end{tabular}

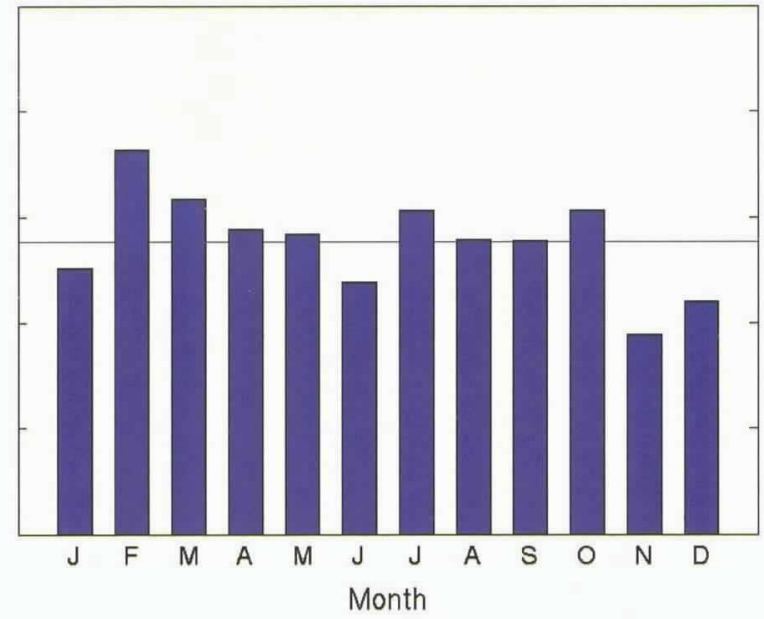

Figure 2. Scientists from the Bermuda Biological Station for Research and the University of Hawaii have gone to sea regularly since October 1988 to observe a broad spectrum of physical and biogeochemical phenomena and to conduct plankton rate experiments. BATS has succeeded in fielding cruises each month over more than 11 years with a total of 701 days at sea. Despite this remarkable achievement, the mean at-sea observation period is only $16 \%$ ( 1 day in 6 ) of each month. The HOT program has had several gaps in its record, most notably November-December 1993, June-July 1994 and October-November 1997 because of difficulties in scheduling a research vessel. HOT has totaled 606 days at sea, and its mean at-sea observation period is $14 \%$ (1 day in 7) of each month.

stantially on both annual and decadal scales (Figure 3) but is generally around 250 to $500 \mathrm{~m}$ deep. Conditions near Hawaii are quite stable, on the other hand. At HOT Station ALOHA, wintertime mixed-layer depth rarely exceeds $125 \mathrm{~m}$ and is generally much shallower (Figure $3)$. This difference is linked to the more southerly latitude of HOT relative to the winter storm track and location relative to continental land mass. Surface waters at Station ALOHA receive little in the way of inorganic nutrients from the depths; the result is chronic depletion of nutrients in near-surface waters. As Figure 3 shows, wintertime mixed-layer nitrate concentrations for BATS range between 0.5 and $5 \mu \mathrm{M}$, whereas they are less than $0.03 \mu \mathrm{M}$ and more typically less than 0.01 $\mu \mathrm{M}$ for HOT.

Based on our pre-JGOFS understanding of ocean biogeochemistry, one would predict that the annual rates of primary production, the total annual export of organic matter and the comparison of exported carbon with total photosynthesis (the so-called export or " $\mathrm{e}$ "ratio) would all be much greater for BATS than for HOT. These biological rates might also be expected to exhibit greater interannual variability at BATS as a result of fluctuations in wintertime nutrient entrainment into the mixed-layer (Figure 3). However, the time-series observations are inconsistent with these simple ecological predictions (Table 2 and Figure 4). Both the climatological mean and range of measured values for primary production, particulate carbon flux and e-ratio, vary unexpectedly at both sites, and the ranges are nearly indistinguishable. Thus, there are basic processes controlling oceanic variability that are outside of our simple paradigms and not resolved by JGOFS sampling approaches. There is still much to be learned about the 

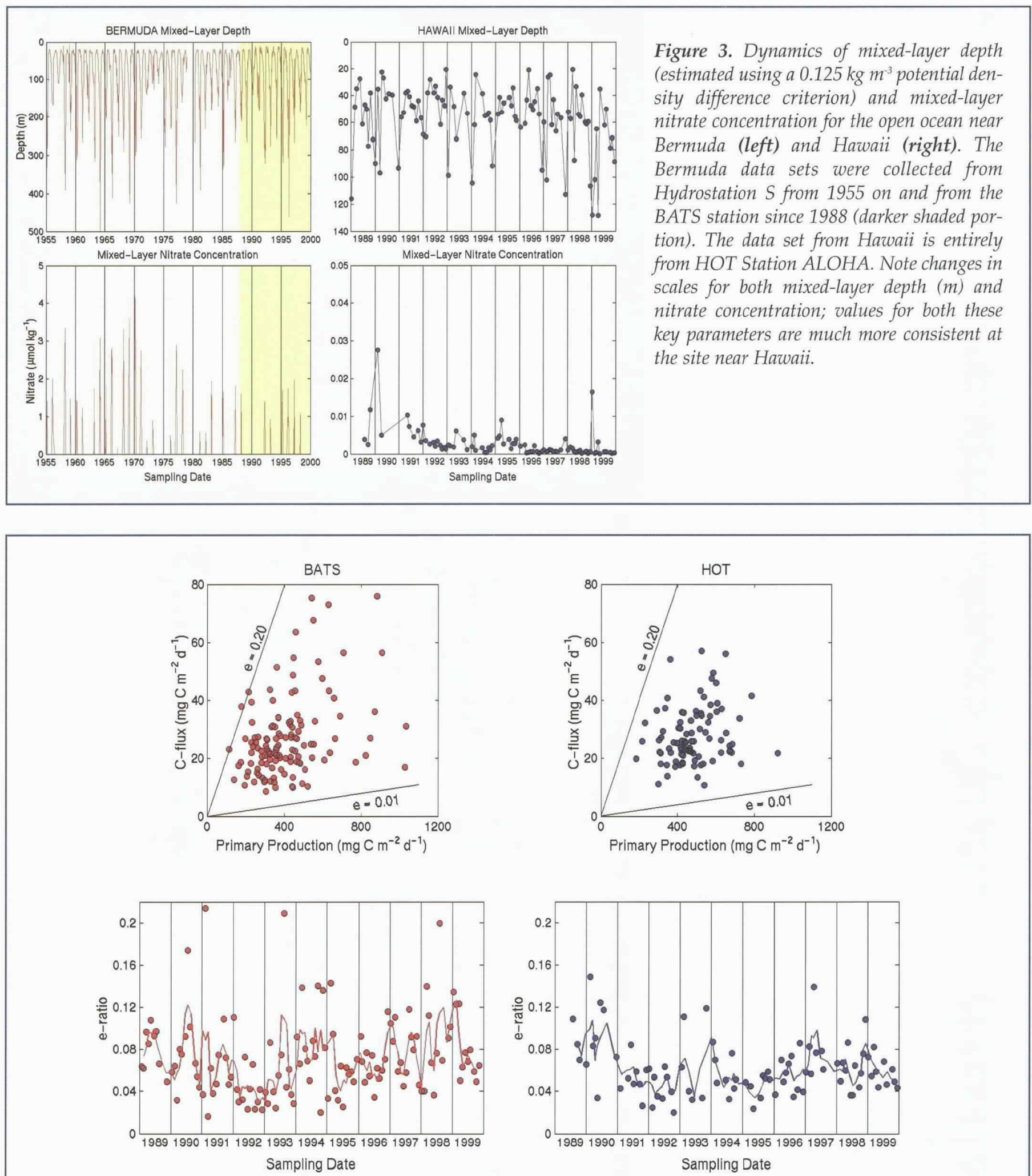

Figure 4. Biological pump dynamics at the U.S. JGOFS time-series sites. (top) Primary production (measured by the ${ }^{14} \mathrm{C}$ technique; Table 1) versus particulate carbon flux (measured by free drifting sediment traps; Table 1) at the base of the euphotic zone (C-Flux) for the 11-year observation periods at BATS (left) and HOT (right). The solid lines show constant e-ratio (C-flux $\div$ primary production) values of 0.2 and 0.01 for comparison. Note the poor correlation between these two parameters, which were thought, a priori, to be tightly coupled in the ocean. As shown in the (bottom) 11-year export ratio (e-ratio) records for the two sites. Each datum represents the e-ratio for the cruise noted. The solid line is the 3-point running mean e-ratio, shown here to indicate temporal trends in the data sets. A statistical summary of these time-series data is presented in Table 2. 


\section{Low-frequency Climate Variability And JGOFS}

James Christian

University of Maryland

College Park, Maryland USA

Climate variability exists on a variety of time scales. Interannual modes such as the El Niño-Southern Oscillation (ENSO) and the North Atlantic Oscillation (NAO) coexist and interact with lower-frequency variations that occur over periods of decades to centuries. Upper-ocean temperatures, for example, show variations in the decadal-and interdecadal (15-30 year) ranges. Proxy records such as tree rings also suggest recurrent fluctuations with periods of 50-100 years. In short data records, these lower-frequency signals are indistinguishable from secular trends.

At frequencies lower than those of ENSO cycles, upper-ocean temperature variability is dominated by the interdecadal mode (White and Cayan, 1998), which in the North Pacific corresponds to the "Pacific Decadal Oscillation" (PDO). This mode has a spatial structure somewhat similar to the more familiar ENSO mode; warming of the tropical Pacific coincides with cooling in the northwest Pacific. PDO reversals, expressed as abrupt "regime shifts," have been documented throughout the $20^{\text {th }}$ century, most recently in 1976. The "phase" of the PDO occasionally reverses itself for a few years in the intervals between these regime shifts, as occurred in 1989-91, coinciding with the first few years of the U.S. JGOFS time-series observations. Thus any short-term ocean observing program may derive a misleading picture of the system under study.

The U.S. JGOFS time-series studies have provided some of the first biogeochemical ocean data that document the effects of interannual-to-interdecadal variability (see Karl et al., this issue). Even after more than a decade, however, these studies have not adequately resolved the dominant climate variability; the interannual ENSO and NAO modes, modulated by lower-frequency variability, have been predominantly in one phase (positive NAO, negative ENSO) throughout the period of observations.

The JGOFS time-series programs have documented significant interannual variability in ocean biogeochemistry. These changes are modulated by lower-frequency climate variability through mechanisms that are poorly understood. Continued high quality, well-calibrated observations are necessary for proper testing of predictive models of ocean biogeochemistry. Even assuming robust representations of the biogeochemical response to changes in physical climate, the modulation of seasonal-to-interannual variability by lower-frequency variability contains nonlinearities and potential surprises. Ecosystem change in response to changing climate creates a significantly more intractable problem, for which current models are almost certainly inadequate.

Low-frequency variability is only beginning to be understood; in fact the evolution of scientific understanding of these processes has occurred largely within the lifetime of JGOFS. Interpretation of the time-series data records in the context of climate variability is thus a subject of ongoing investigation. The time-series studies have shown that observations made on individual cruises are embedded in a complex web of processes that require sustained investigation to understand. Time-series observations have been a critical component of JGOFS and will continue to be essential to the success of future ocean biogeochemistry programs.

Reference

White, W.B. and D.R. Cayan, 1998: Quasi-periodicity and global symmetries in interdecadal upper ocean temperature variability. J. Geophys. Res., 103, 21335-21354.

basic workings of the ocean's carbon pump (see Ducklow et al., this issue; Berelson, this issue).

The water column between 200 and $1000 \mathrm{~m}$, sandwiched between the sunlit surface waters and the dark abyss, has been termed the "twilight zone." In this zone, the least studied or understood portion of the water column, inorganic nutrients such as nitrate and phosphate are regenerated from the particulate organic matter that settles from above. The Bacteria begin to make way for the Archaea. Below approximately $500 \mathrm{~m}$, the Archaea equal the heterotrophic bacteria in numbers and biomass (Karner et al., 2001). Unfortunately, none of these twilight zone microorganisms have been cultured as yet, so their physiological characteristics and ecological niches are not yet known.

A comparison of the nitrate versus depth profiles from BATS and HOT shows generally similar trends of increased nitrate with increased depth (Figure 5).
However, closer inspection reveals a much steeper concentration versus depth gradient near Hawaii and a much higher nitrate concentration at any given depth below $200 \mathrm{~m}$ (Figure 5). This finding has important implications for our understanding of nitrate transport by advection, diffusion and turbulent mixing.

Perhaps more relevant to the efficient functioning of the biological pump, the molar ratios of nitrate to phosphate $(\mathrm{N}: \mathrm{P})$ in the twilight zone vary over time, especially at the BATS site, as well as over depth. At Bermuda the molar ratios of $\mathrm{N}: \mathrm{P}$ decrease from values $>25$ to approximately 15 below $200 \mathrm{~m}$. At Hawaii, the $\mathrm{N}: \mathrm{P}$ molar ratios are more constant for a given depth horizon and exhibit an opposite trend, showing increases with increasing water depth between 200$1000 \mathrm{~m}$ (Figure 5). These fundamental differences reflect a complex balance between production and export processes, as well as between particle export 


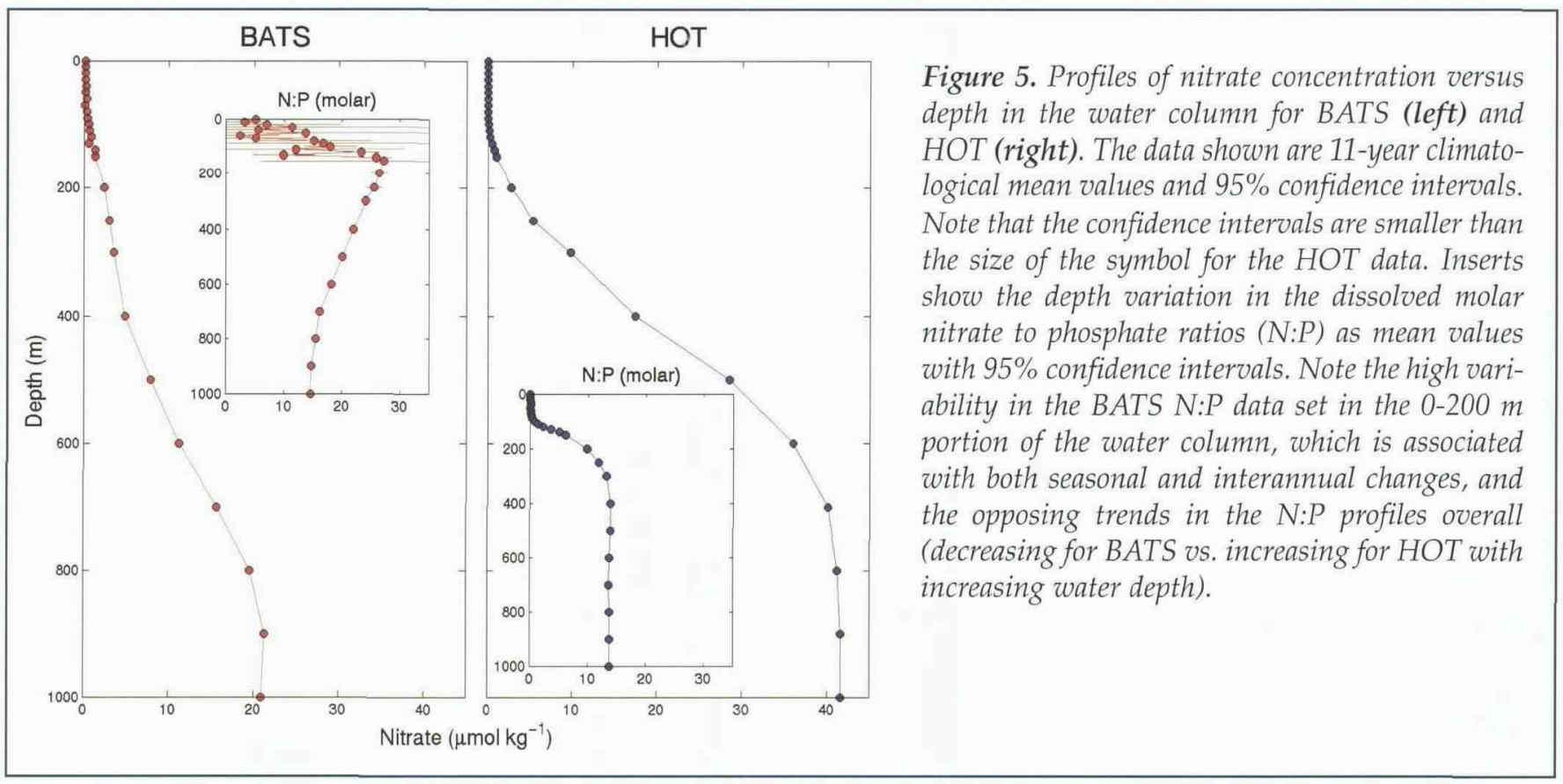

and remineralization. At $\mathrm{N}: \mathrm{P}$ ratios below 16, new organic matter production is likely to be nitrogen limited, which favors specialized microorganisms that are able to derive their metabolic nitrogen needs from the relatively inert but inexhaustible supply of dissolved nitrogen gas (see Michaels et al., this issue).

One cannot compare data sets from the upper part of the twilight zone with contemporaneous surfaceocean rates and processes in a straightforward manner, because these mid-water data sets measure signals that have been integrated over decades. Suffice it to say that these and other comparative data sets from Bermuda and Hawaii suggest that nutrient dynamics in the two major subtropical ocean gyres of the Northern Hemisphere have vastly different biogeochemical processes and ecological controls. Resolution of these differences is a high priority for future research.

\section{Surprises, Riddles and Brain-teasers}

Because there were no comparable biogeochemical

\section{Table 3}

Inorganic carbon pool dynamics at the U.S. JGOFS BATS and HOT time-series stations'

\begin{tabular}{l|l|l|l|l|l} 
Location & $\begin{array}{l}\text { Measurement } \\
\text { Period }\end{array}$ & $\begin{array}{l}\text { Annual N-DIC } \\
\text { Range }^{2} \\
(\mu \mathrm{mol} \mathrm{kg})\end{array}$ & $\begin{array}{l}\text { Secular N-DIC } \\
\text { Change } \\
\left(\mu \mathrm{mol} \mathrm{kg-1} \mathrm{rr}^{-1}\right)\end{array}$ & $\begin{array}{l}\text { Annual } \mathrm{fCO}_{2} \\
\text { Range } \\
(\mu a t m)\end{array}$ & $\begin{array}{l}\text { Secular } \mathrm{fCO}_{2} \\
\text { Change } \\
\left(\mu a t m \mathrm{yr}^{-1}\right)\end{array}$ \\
\hline
\end{tabular}

\begin{tabular}{l|l|l|l|l|l}
\hline BATS & $\begin{array}{l}10 / 88 \text { to } 12 / 99 \\
(11 \mathrm{yr})\end{array}$ & $30-40$ & $\begin{array}{l}+1.23 \\
(+0.61 \text { to }+1.85) \\
n=136\end{array}$ & $\begin{array}{l}60-120 \\
(-0.83 \text { to }+3.16) \\
n=118\end{array}$ \\
\hline HOT & $\begin{array}{l}10 / 88 \text { to } 12 / 99 \\
(11 \mathrm{yr})\end{array}$ & $15-20$ & $\begin{array}{l}+1.18 \\
(+0.79 \text { to }+1.58) \\
n=94\end{array}$ & $\begin{array}{l}25-60 \\
(+1.59 \text { to }+3.44) \\
n=86\end{array}$
\end{tabular}

Data from Bates (2001) and Dore et al. (2001) as well as unpublished results from both time-series programs.

Data are presented as the measured range (minima and maxima) or as mean and, in parentheses,

$95 \%$ confidence intervals, as shown. $n=$ number of observations.

${ }^{2} \mathrm{~N}$-DIC is dissolved inorganic carbon concentration normalized to a constant salinity of 35.0 


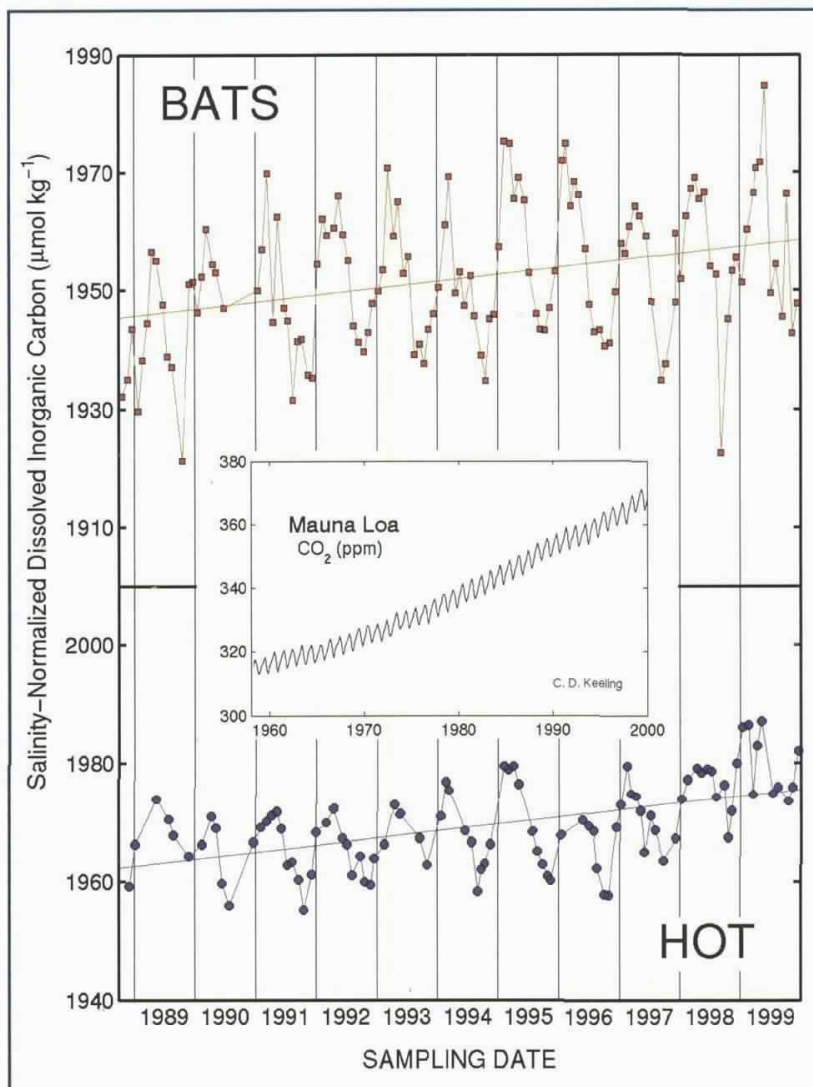

Figure 6. The 11-year record of mixed-layer dissolved inorganic carbon (DIC), normalized to a salinity of 35.0, for BATS (upper curve) and HOT (lower curve). The larger annual variation at BATS is associated with the greater seasonal temperature range and the seasonal variation in the production of organic matter production at that site. The increase in DIC at both sites over 11 years $\left(\right.$ BATS $=+1.23 \mu \mathrm{mol} \mathrm{kg}{ }^{-1} \mathrm{yr}^{-1}$, HOT $=+1.18$ $\left.\mu m o l \mathrm{~kg}^{-1} \mathrm{yr}^{-1}\right)$ tracks the increase in atmospheric carbon dioxide $\left(\mathrm{CO}_{21}\right)$, shown in the center inset, measured by C.D. Keeling at Mauna Loa, Hawaii, since 1958. A statistical summary of these time-series data sets is presented in Table 3.

data sets gathered on equivalent time scales before the BATS and HOT programs got underway, we had no reliable predictions about what we might find. Although predictions of the ocean's capacity to absorb anthropogenic carbon dioxide could be made on the basis of thermodynamic principles and gas-transfer model calculations, there was no explicit proof that changes in levels of dissolved inorganic carbon (DIC) could actually be detected in the ocean until the BATS and HOT time-series data sets were available (Figure 6). Because natural seasonal and interannual variations in DIC are huge compared to the increase resulting from human activities, accurate and reproducible repeat measurements were required for nearly a decade before we could be certain, as we now are, that the upper water-column inventory of DIC is increasing (Table 3).
Marine scientists working off Bermuda and Hawaii have now observed other previously known but poorly-constrained processes in much greater detail than ever before. To our surprise, and delight, the timeseries observations routinely reveal previously undescribed phenomena, including novel ecological pathways and climate-driven biogeochemical connections. This new knowledge and its contribution to the shifting ecological paradigms have made these intensive observational field efforts a labor of love.

One of the major enigmas so far is the apparent uptake and removal of DIC from the water column at both time-series sites during the summer months despite the lack of nitrate, essential for the transformation of inorganic carbon into organic matter. Because any hidden source of nitrate would also contain inorganic carbon, this conundrum cannot be explained in terms of missed nutrient entrainment events. One hypothesis is that the "missing" nitrogen required to sustain these ecosystems may be derived from the metabolic activities of microorganisms that fix nitrogen in the form of $\mathrm{N}_{2}$ from the atmosphere (Michaels et al., this issue). The evidence for $\mathrm{N}_{2}$ fixation comes from several independent sources, some based on biological processes reflecting contemporaneous rates and processes and others based on geochemical assessments with integration time scales of years to decades.

Others have hypothesized that $\mathrm{N}_{2}$ fixation in the ocean may be controlled by the atmospheric deposition of iron, which itself varies in response to changing climate patterns. The transport and distribution of atmospheric dust is also affected by human factors, including population demographics, economic trends and landuse patterns. These complex natural and anthropogenic interactions, with multiple potential feedback loops, affect biogeochemical variability in the otherwise "stable and homogeneous" biomes that we initially sought to monitor and understand. A major scientific challenge is to produce a new ecumenical theory of nutrient dynamics in the sea, one that can be used in a robust conceptual and mathematical framework for accurate prediction of the response of the ocean carbon cycle to climate change and human activities.

We think that wind, heat flux and rainfall changes associated with climate variations have had measurable and significant effects on biogeochemical processes at both BATS and HOT stations. At the BATS site, cold water anomalies in 1992 and 1995 were associated with deeper mixed-layers, higher rates of annual primary production and higher concentrations of near-surface DIC. These events were linked to variations in largescale climate patterns, specifically NAO and ENSO. At the HOT Station ALOHA, the long-term negative Southern Oscillation Index (SOI) conditions of the 1990s (Figure 7), coupled with an independent extended warm phase of the PDO, have contributed to interdecadal changes in the North Pacific subtropical gyre habitat. These changes, in turn, have encouraged the growth of $\mathrm{N}_{2}$-fixing microorganisms, leading to a shift 


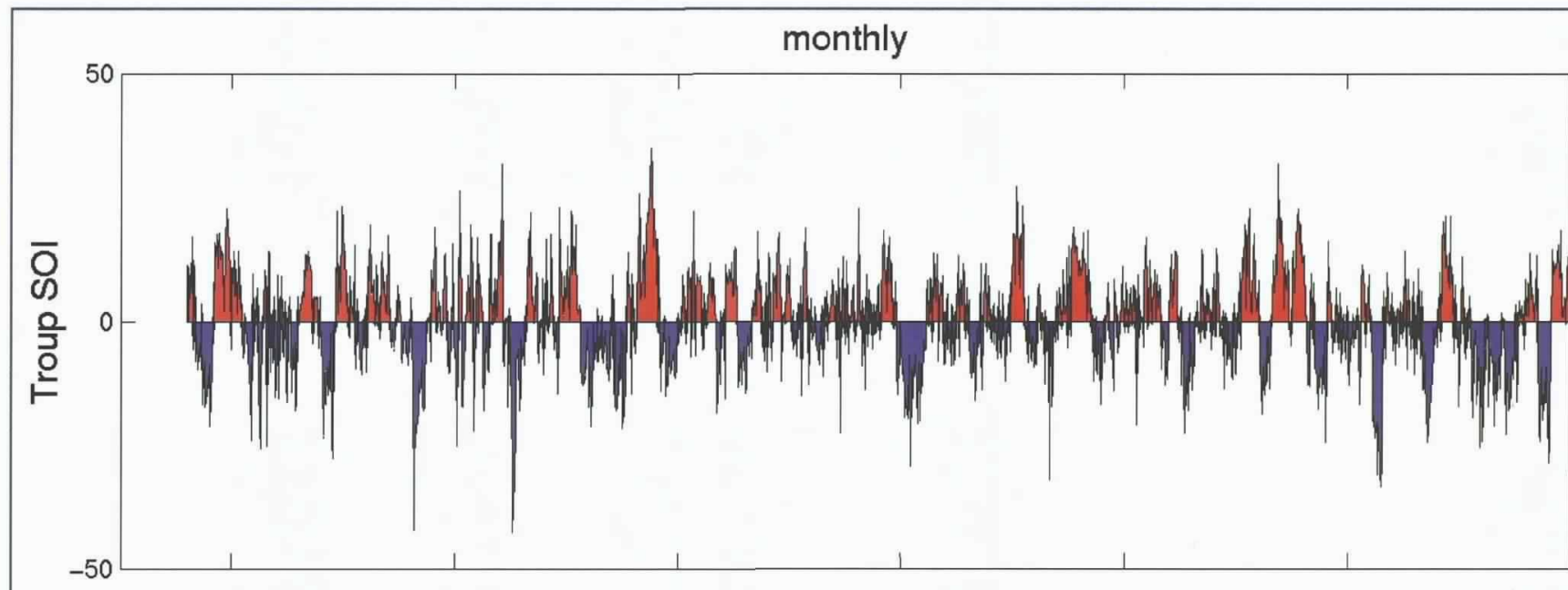

10 year

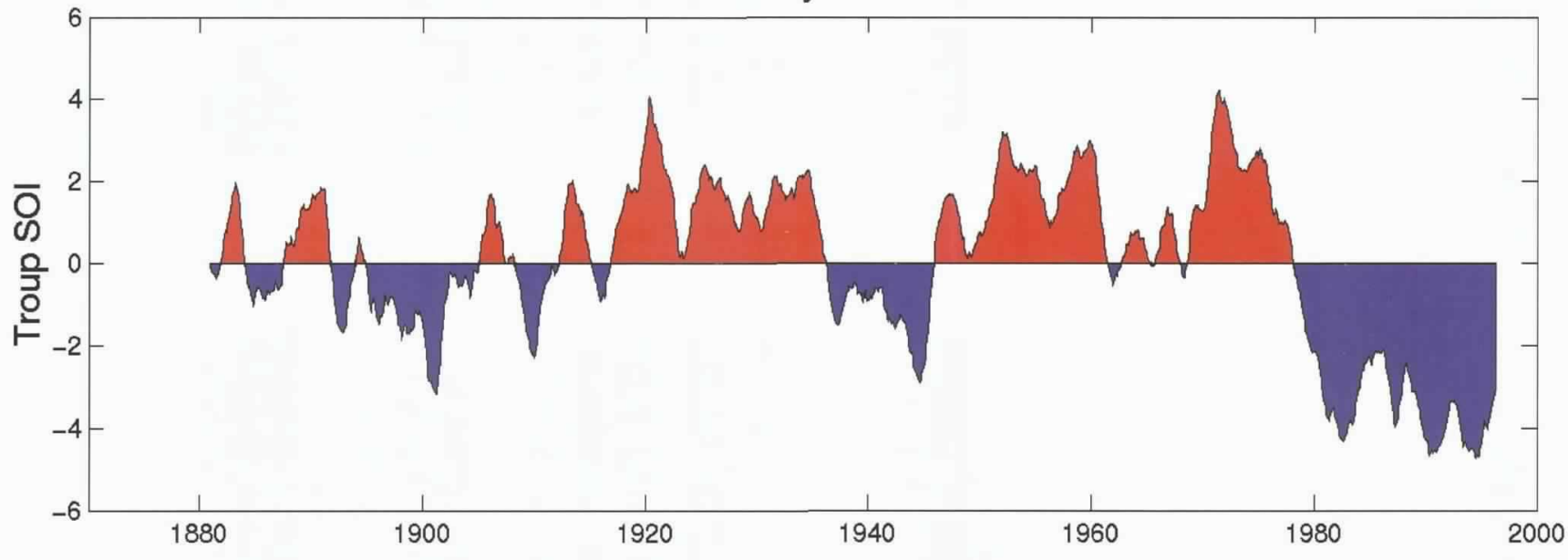

Figure 7. The pulse of the planet's climate system as measured by the Troup Southern Oscillation Index (SOI). Periods characterized by a negative SOI tend to favor El Niño conditions, which have wide-ranging environmental effects, both at sea and on land. The top graph shows the mean monthly Troup SOI record, and the bottom graph presents the 10-year running mean of the same climate record to filter out the high-frequency variations and to focus on the low frequency signals that may be more important for biogeochemical processes and ecological change. There are two key points to consider in the context of JGOFS. The first is that HOT and BATS observations have been made entirely during an extended period with negative SOI values, which are correlated in general with warmer than average sea-surface temperatures in the subtropical northeastern Pacific and elsewhere. The second is that the post-1980 duration of this warm period is unprecedented in the 100-year data set. This finding suggests that ocean conditions during the JGOFS era may not be representative of $20^{\text {th }}$ century mean climatological or ecological conditions.

from the nitrogen-limited ecosystem that prevailed before the 1980 s to a phosphorus- or iron-limited system during the JGOFS era (Karl, 1999). These fundamental changes, which have occurred at both sites, have affected local, regional and perhaps global carbon cycle dynamics in the ocean.

\section{The Ocean Carbon Cycle "Universities"}

Since the JGOFS time-series programs began, sci- entists associated with them have created and disseminated knowledge, organized and hosted interdisciplinary workshops and symposia, and facilitated technical training and information exchange. Each site has been the focal point for a large number of related studies that have built on the core research and, in turn, contributed to that common body of understanding. The time-series sites have functioned as ocean carbon cycle "universities," with the time-series "faculty" engaged 
in the academic triad of research, teaching and community service.

Among the unique aspects of the JGOFS timeseries programs are their roles as facilitators of complementary ocean and atmospheric research and as test-beds for the development and evaluation of novel sensors and other instruments. The extensive and diverse lists of ancillary investigators who have benefited from the core measurement programs testify to the successes of BATS and HOT in these roles. Full and free access to all time-series data in a timely manner is a critical component of both the successful collaboration of these two programs and the widespread use of these data by outside investigators and modelers. The time-series programs have also served as floating classrooms for public education, from kindergarten to elderhostel.

\section{Prospectus For The Future}

At the beginning of the JGOFS era, we considered our general understanding of open-ocean subtropical gyres to be nearly complete. These large ecosystems were thought to be stable in time and coherent in space, supporting homogeneous plankton communities that were well-tuned to their habitats and fairly resistant to natural physical forcing. We now recognize these regions as fundamentally different biomes; they are dynamic, variable and poised for ecological opportunity.

BATS and HOT scientists continue to explore the hidden secrets of the marine carbon cycle. Although it is difficult to predict the direction of ocean carbon cycle research, one thing is abundantly clear. Time-series programs need to be preserved, enhanced and expanded to other key sites. These programs and related components of the emerging global ocean observing network will continue to provide opportunities for both basic and applied research well into the future.

At the beginning of the JGOFS era, we had no idea that we would uncover so much biogeochemical variability in the ocean or achieve so many novel insights in connection with the time-series programs. As the data sets grow, new scales of variability will likely become evident. But BATS and HOT are relatively short in length compared to what will be required for a comprehensive understanding of the effects of climate on the ocean's carbon cycle. Extending these field studies over more decades will help us reach firm conclusions that will lead us to accurate ecological predictions. Time to head back to sea.

\section{Acknowledgments}

Sufficient space does not exist to express our collective debt of gratitude to the scientists, technical staff, data managers, students and ship officers and crew who have assisted in the collection, analysis and interpretation of the BATS and HOT data sets. We likewise thank our public and private sector sponsors for their generous financial support, especially the Division of
Ocean Sciences of the National Science Foundation. Since the beginning of JGOFS, the time-series programs have benefited from the oversight of the JGOFS Scientific Steering Committee and from three ad hoc time-series committees chaired by Steve Emerson, Tommy Dickey and Jim McCarthy. Finally, we thank Ken Buesseler, Mardi Bowles and Mary Zawoysky for their efforts in preparing this special issue on the U.S. JGOFS research program. This is U.S. JGOFS Contribution Number 677.

\section{References}

Azam, F., T. Fenchel, J.G. Field, R.A. Meyer-Reil and F. Thingstad, 1983: The ecological role of water column microbes in the sea. Mar. Ecol. Prog. Ser., 10, 257-263.

Bates, N.R., 2001: Interannual variability of oceanic $\mathrm{CO}_{2}$ and biogeochemical properties in the Western North Atlantic subtropical gyre. Deep-Sea Res. II, 48, 1507-1528.

Béjà, O., E.N. Spudich, J.L. Spudich, M. LeClerc and E.F. DeLong, 2001: Proteorhodopsin phototrophy in the ocean. Nature, 411, 786-789.

Chisholm, S.W., R.J. Olson, E.R. Zettler, R. Goericke, J.B. Waterbury and N.A. Welschmeyer, 1988: A novel free-living prochlorophyte abundant in the oceanic euphotic zone. Nature, 334, 340-343.

DeLong, E.F., 1992: Archaea in coastal marine environments. Proc. Natl. Acad. Sci. USA, 89, 5685-5689.

Dore, J.E., C.J. Carrillo, D.V. Hebel and D.M. Karl, 2001: Carbon cycle observations at the Hawaii Ocean Timeseries Station ALOHA. In: Proceedings of the PICES North Pacific $\mathrm{CO}_{2}$ data synthesis symposium. $\mathrm{Y}$. Nojiri and $\mathrm{R}$. Feely, eds., Tsukuba, Japan, October 2000, in press.

Dugdale R.C. and J.J. Goering, 1967: Uptake of new and regenerated forms of nitrogen in primary productivity. Limnol. Oceanogr., 12, 196-206.

Eppley, R.W. and B.J. Peterson, 1979: Particulate organic matter flux and planktonic new production in the deep ocean. Nature, 282, 677-680.

Johnson, P.W. and J.McN. Sieburth, 1979: Chroococcoid cyanobacteria in the sea: a ubiquitous and diverse phototrophic biomass. Limnol. Oceanogr., 24, 928-935.

Karl, D.M., 1999: A sea of change: Biogeochemical variability in the North Pacific subtropical gyre. Ecosystems, 2, 181214.

Karl, D.M. and A.F. Michaels, eds., 1996: Ocean Time-series: Results from the Hawaii and Bermuda Research Programs. Deep-Sea Res. II, Topical Studies in Oceanography, 43.

Karner, M.B., E.F. DeLong and D.M. Karl, 2001: Archaeal dominance in the mesopelagic zone of the Pacific Ocean. Nature, 409, 507-510.

Kolber, Z.S., F.G. Plumley, A.S. Lang, J.T. Beatty, R.E. Blankenship, C.L. VanDover, C. Vetriani, M. Koblizek, C. Rathgeber and P.G. Falkowski, 2001: Contribution of aerobic photoheterotrophic bacteria to the carbon cycle in the ocean. Science, 292, 2492-2495.

Pomeroy, L.R., 1974: The ocean's food web: A changing paradigm. BioScience, 24, 409-504.

Siegel, D.A., D.M. Karl and A.F. Michaels, eds., 2001: HOT and BATS: Interpretations of Open Ocean Biogeochemical Processes. Deep-Sea Res. II, Topical Studies in Oceanography, 48. 